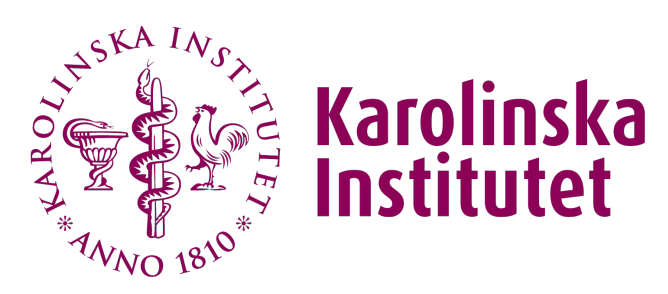

Karolinska Institutet

http://openarchive.ki.se

This is a Peer Reviewed Published version of the following article, accepted for publication in European Journal of Epidemiology.

2017-03-28

\title{
Registers of the Swedish total population and their use in medical research
}

Ludvigsson, Jonas F; Almqvist, Catarina; Edstedt Bonamy, Anna-Karin; Ljung, Rickard; Michaëlsson, Karl; Neovius, Martin; Stephansson, Olof; Ye, Weimin

Eur J Epidemiol. 2016 Feb;31(2):125-36.

http://doi.org/10.1007/s10654-016-0117-y

http://hdl.handle.net/10616/45635

If not otherwise stated by the Publisher's Terms and conditions, the manuscript is deposited under the terms of the Creative Commons Attribution-NonCommercial-NoDerivatives License (http://creativecommons.org/licenses/by-nc-nd/4.0/), which permits non-commercial re-use, distribution, and reproduction in any medium, provided the original work is properly cited, and is not altered, transformed, or built upon in any way. 


\section{(19) \\ Karolinska Institutet}

This is an author produced version of a paper published by European Journal of Epidemiology. This paper has been peer-reviewed but does not include the final publisher proofcorrections or journal pagination.

Registers of the Swedish total population and their use in medical research. Eur J Epidemiol. 2016 Feb;31(2):125-36.

Ludvigsson, J.F.; Almqvist, C.; Edstedt Bonamy, A-K.; Ljung, R.; Michaëlsson, K.; Neovius, M.; Stephansson, O.; Ye, $\mathbf{W}$.

\section{DOI: $10.1007 / s 10654-016-0117-y$}

Access to the published version may require subscription. Published with permission from: Springer Nature 
1 Registers of the Swedish total population and their use in medical research

3 Authors' affiliations

4 Jonas F Ludvigsson*\# $\sim^{\text {a }}$, Catarina Almqvist* ${ }^{*}$, Anna-Karin Edstedt Bonamy $\$$, Rickard Ljung§,

5 Karl Michaëlsson†, Martin Neovius], Olof Stephansson $\int_{\ddagger}^{\dagger}$, Weimin Ye*

6

7

8 * Department of Medical Epidemiology and Biostatistics, Karolinska Institutet, Sweden

9 \# Department of Paediatrics, Örebro University Hospital, Sweden

$10 \approx$ Division of Epidemiology and Public Health, School of Medicine, University of Nottingham,

11 UK

$12 \infty$ Astrid Lindgren Children's Hospital, Karolinska University Hospital, Stockholm, Sweden

13 S Clinical Epidemiology Unit, Department of Medicine Solna, Karolinska Institutet, Sweden

$14 \S$ Unit of Epidemiology, Institute of Environmental Medicine, Karolinska Institutet, Stockholm,

15 Sweden

$16 \uparrow$ Department of Surgical Sciences, Uppsala University, Sweden

$17+$ Department of Women's and Children's Health, Karolinska Institutet and Hospital, Sweden

$20{ }^{a}$ Correspondence and reprint requests:

21 Jonas F. Ludvigsson

22 Department of Medical Epidemiology and Biostatistics, Karolinska Institutet, 17177 Stockholm,

23 Sweden

24 Phone: $+46(0)$ 8-52480000

25 Fax: +46 (0) 8-314975

26 E-mail: jonasludvigsson@yahoo.com

29 Running head: Total Population Registers in Sweden 
1 Abbreviations:

2 PIN, Personal Identity Number

3 PR, Population Register

$4 \quad$ PR-Tax, Population Register (maintained by the Swedish Tax Agency)

5 TPR, Swedish Total Population Register (maintained by Statistics Sweden)

6

7 Manuscript version: Dec 23, 2015.

8 Word count: 5303. Abstract: 256.

9 Tables: 1 . Figures: 3 . Character count for title: 75

10

11 Writing Assistance: None.

14 Declaration of interest: None.

15 


\section{ABSTRACT}

2 The primary aim of the Swedish national population registration system is to obtain data that (i)

3 reflect the composition, relationship and identities of the Swedish population and (ii) can be used

4 as the basis for correct decisions and measures by government and other regulatory authorities.

5 For this purpose, Sweden has established two population registers: (i) The Population Register,

6 maintained by the Swedish National Tax Agency ("Folkbokföringsregistret"); and (ii) The Total

7 Population Register (TPR) maintained by the government agency Statistics Sweden ("Registret

8 över totalbefolkningen"). The registers contain data on life events including birth, death, name

9 change, marital status, family relationships and migration within Sweden as well as to and from

10 other countries. Updates are transmitted daily from the Tax Agency to the TPR.

11 In this paper we describe the two population registers and analyse their strengths and weaknesses.

12 Virtually $100 \%$ of births and deaths, $95 \%$ of immigrations and $91 \%$ of emigrations are reported

13 to the Population Registers within 30 days and with a higher proportion over time. The over-

14 coverage of the TPR that is primarily due to underreported emigration data has been estimated at

15 up to $0.5 \%$ of the Swedish population. Through the personal identity number, assigned to all

16 residents staying at least 1 year in Sweden, data from the TPR can be used for medical research

17 purposes, including family design studies since each individual can be linked to his or her

18 parents, siblings and offspring. The TPR also allows for identification of general population

19 controls, participants in cohort studies, as well as calculation of follow-up time. 


\section{INTRODUCTION}

2 In Sweden, there are two Population Registers (PRs) tracking Swedish residents: the Population

3 Register (PR-Tax) and the Total Population Register (TPR). The former is maintained by the

4 Swedish Tax Agency and the latter by Statistics Sweden. Both registers are instrumental to

5 epidemiological research in Sweden, and can be linked to other health registers through the

6 personal identity number (PIN)[1]. The current paper aims to describe vital aspects of the

7 Swedish PRs, and builds on our previous paper about the PIN[1].

9 The aim of the Swedish national population registration (Swedish: folkbokföring) and the PR-

Tax is to obtain data that (i) reflect the composition, family relationship and identities of the

Swedish population and (ii) can be used as the basis for correct decisions and measures (e.g.,

12 taxation and allowances) by government and other organisations. Major events in an individual's

13 life, such as birth, death, marriage, name changes, family relationships, change of sex, but also

14 place of residence are continuously recorded in the national registration. Being recorded in the

15 Swedish PRs is tied to both rights and duties, including social benefits, paying tax and the right to vote. Figure 1 gives an overview of the Swedish population since 1968 according to year and age group. The population in Sweden was 9,775,572 on April 30, 2015.

The aim of the TPR is to produce statistics and most researchers will only interact with the TPR. Although the PR-Tax and the TPR are two different registers, they share all variables and are therefore jointly described in this paper.

\section{History of the Population Registers}

24 The Church of Sweden has kept local registers of their parish members since the $17^{\text {th }}$ century [2].

25 This procedure allowed the church, and consequently the Swedish State, to collect taxes and 26 enrol soldiers.

28 In 1991, the Swedish Tax Agency took over the responsibility for the national registration and the Population Register from the Church of Sweden. The Tax Agency is organised around local units collecting data (Figure 2). Local data are then stored in the national PR-Tax. 
1 Most people who are born in Sweden or move to the country are recorded in the national PR-Tax

2 (exceptions are described in the section about the PIN). On entering the register, the individual is

3 assigned a PIN [1]. The PR-Tax also distributes population information (including address

4 information) to various government agencies. For these reasons, Swedish residents moving within

5 Sweden have to notify the Tax Agency when they change their address.

6 Five times a week the Tax Agency distributes new data from the PR-Tax to relevant government

7 authorities, among them the Swedish Migration Board, the Swedish Pension Agency and

8 Statistics Sweden (Figure 2). Each year, approximately three million updates are sent from the

9 Swedish Tax Agency. Transmission of data to other government agencies is regulated by law

10 (SFS1991:481 and SFS2001:100).

12 Certain updates (primarily names and addresses) of the PR-Tax are accessible to a number of actors, including private customers through a service called "SPAR" (the Swedish Population and Address Register). This service allows, for instance, mail order companies to contact a large number of potential customers. Government agencies, banks and insurance companies have access to additional data, whereas some highly sensitive data are only distributed to the Police and the Customs Office.

The TPR (Swedish: Registret över TotalBefolkningen, RTB) started in 1968 after a large part of the population data was computerised in 1967. A complete year-specific version of the TPR is available for each year since 1968 (certain data are actually available since 1961).

The variables in the PRs have remained relatively constant since 1968 (Table 1), with a few changes. Until 1973, birth number was only recorded for births within a marriage while birth order signifies the order of births in the same mother. In 1974, regulations on divorce shortened the administrative time, resulting in an increase in the number of registered divorces in 1974 and 1975. Rules for citizenship of children whose parents had different citizenship changed in 1975.

28 Regulations for a widow's pension were changed in 1990, which led to a substantial increase in the number of married couples the year before (1989). Since 2011, the TPR contains information on apartment (some data available since 2006). 

National Land Survey (Swedish: Lantmäteriet), and then transmitted to Statistics Sweden. This

2 allows Statistics Sweden to calculate household-specific information such as size and type of 3 dwelling and number of children per household. It also makes it possible to identify cohabitants.

\section{CONTENT OF THE POPULATION REGISTERS (PRs)}

\section{Birth}

8 At birth, the midwife or the hospital reports the birth to the PR-Tax. The child is automatically 9 assigned a PIN and the Tax Agency records the citizenship of the child as well as the newborn's family name. If the parents (couple) are married, the husband is assumed to be the biological father of the child, and parents will automatically have joint custody. If the couple is not married,

12 paternity is confirmed through a notification to the Social Welfare Committee (Swedish:

Socialnämnden) signed by both parents. At that stage, non-married parents are also asked to report whether they want to have joint custody of the child. If, instead, paternity is confirmed through a court decision, the court will inform the Swedish Tax Agency of its decision. Further, a woman living with the biological mother can be registered as a "parent", but not as the biological mother (for a same-sex parent to be registered as a "parent", the women have to be married, or

18 live together; similar rules apply to male parents).

\section{Death}

21 When a person in Sweden dies, the physician confirming the death has to submit a death certificate to the Tax Agency. For Swedish citizens who die abroad, the Swedish embassy or consulate in the relevant country must inform the Tax Agency about the death. However, if a foreign citizen residing in Sweden dies abroad (outside Sweden), the family of the deceased is not obliged to inform the Tax Agency about the death (but often the relatives do so).

\section{Emigration}

28 Individuals who move outside Sweden and plan to stay abroad for $\geq 1$ year should be $d e$ registered from the PRs. This rule also applies to individuals who plan to stay abroad for less than 1 year but then decide to stay away longer. Moving abroad does not influence citizenship.

31 Individuals spending more than a year abroad are not removed from the PRs provided that they 
are working in the service of the Swedish state, or if absence is due to sudden disease or

2 imprisonment, this also applies to their family members. Swedish priests and missionaries

3 working abroad and their family were previously included in the PRs even if staying abroad for

$4 \geq 1$ year. However, this exemption has been removed. Swedish individuals who work for the

5 European Union (EU) or United Nations, and Swedish students going abroad for $\geq 1$ year because

6 of academic studies are regarded as emigrated and will be removed from the PRs.

8 Special rules for emigration apply to Swedish individuals moving to Denmark, Finland, Iceland 9 or Norway. These individuals will remain in the PRs until the receiving country notifies the Swedish individuals that from now on they will be included in their PR (e.g., in Norway this takes 6 months). Individuals living both abroad and in Sweden can choose to remain in the

12 Swedish PRs provided that they spend at least 1/7 of each year in Sweden (one day per week or equivalent). Emigration and re-immigration do not affect one's PIN (all emigrants retain their

14 PIN).

\section{Immigration to Sweden}

17 Individuals moving to Sweden and planning to stay there for $\geq 1$ year will in most cases be 18 recorded in the PRs, provided that they fulfil certain criteria for work, education or self-support. Until 1998, only the year of immigration was recorded for individuals who had immigrated before 1968 (sometimes not even the year of immigration was recorded).

\section{Migration within Sweden}

All individuals who move within Sweden must notify the Swedish Tax Agency. The place of residency is the place where the individual lives most of the time and where the person sleeps for at least one out of seven nights. Each individual can only have one registered address. This also applies to children with two guardians at different addresses. In 2012, one out of four children $(\mathrm{n}=480,000)$ had separated parents (including those whose parents had never lived together)[3].

28 Of these children, some $35 \%$ had two residences[3].

Children who must relocate because of academic studies will remain being registered with their parents until the age of 18 years or up until 21 years of age if they need to complete elementary

31 school or high school, i.e. non-university studies. A registered address will not be changed 
1 because of hospital admission or imprisonment or because an elderly person has been moved for

2 caring reasons to a retirement home in a different city.

\section{Marriage and divorce}

5 The Swedish PRs record marriages. Marriage of children $<18$ years are however only recognised

6 if both individuals were non-Swedish and $\geq 15$ years at time of marriage (and only then will the

7 marriage be treated on a case-by-case basis).

8 Information about divorce (dissolution of marriage) is submitted by the Swedish district court to

9 the Tax Agency where it is recorded. When the divorce has taken place abroad, those involved in

10 the divorce must inform the Tax Agency.

11 Until 2009 Swedish government agencies also registered "partnership" (and "separated after

12 partnership"). Data on partnership can still be found in the Swedish population registers but no

13 new "partnership data" are entered into the registers after 2009 when marriage in Sweden became 14 gender neutral.

\section{Country of birth}

17 Between 1947 and 2013, children born abroad were regarded as born in Sweden provided that 18 certain conditions of their parents were met. The child was then assigned the same country and parish of birth as that recorded in the mother at the time of birth. For non-Swedes, country of birth is registered with the name of the country at year of birth of each individual (even if that country has ceased to exist, e.g. Soviet Union). Before 1947, country of birth other than Sweden was usually recorded as "foreign-born" without further clarification.

25 The PRs record biological sex. Men are assigned "1" and women " 2 ". The code for sex is 26 generated from an individual's PIN (the second last digit is odd in men and even in women).

27 Since 1972, the sex designation of an individual can be changed after application to the National 28 Board of Health and Welfare. Upon approval of that application, the PIN and the sex in the PRs 29 are replaced. 
2 Among Swedish citizens, only Swedish citizenship is listed. In non-Swedish residents the PRs

3 will record up to three citizenships per person, with the citizenship obtained first in time listed

4 first. Citizenship from states that are not yet acknowledged by the Swedish government is not

5 registered. Since April 1, 2015, the Swedish Tax Agency records a Swedish citizenship for every

6 child born to a Swedish mother or father independent of the country of birth. Before that date,

7 children to Swedish mothers were always given Swedish citizenship but only some children to

8 Swedish fathers (provided the father was married to the mother or if the non-Swedish mother

9 lived in Sweden).

11 If both parents lack Swedish citizenship, a child will be assigned citizenship according to the

12 laws of the country of the parents (the child will not automatically become a Swedish citizen

13 even if born in Sweden). Citizenship does not automatically imply that the child is registered in

14 the PRs. Most children born abroad to Swedish parents will not enter the PRs until moving to

15 Sweden, the exception being children born to certain diplomats or individuals working abroad on

16 behalf of the Swedish State.

17 When a child is adopted in Sweden, both the adoptive parents and the biological parents are

18 recorded in the PRs. After a Swedish court has decided on an adoption, the court will inform the

19 Tax Agency about its decision. In the event an adoption has taken place outside Sweden the

20 Swedish adoptive parents have an obligation to inform the Tax Agency when the child enters

21 Sweden in order for the child to obtain Swedish citizenship.

\section{Special registers based on the TPR}

24 Using the TPR, Statistics Sweden each year produces a number of special registers. Among them 25 are the (i) Multi-generation register (contains individuals born since 1932 and any relationship to 26 biological and adoptive parents)[4], (ii) the Migration register (the most important data in this

27 register are grounds for residence and the reason to immigrate) and (iii) the PIN register[1],

28 which contains all PINs in the TPR since 1968 as well as any PIN recorded in the annual censuses since 1960 or later. This register also contains PIN changes. A detailed description of circumstances when a PIN may be changed has been published elsewhere[1]. 
2 Statistics Sweden provides the TPR with monthly, quarterly and annual data. The monthly

3 version of the TPR is used during one month and then replaced by the next month's TPR. The

4 annual TPR refers to the population on December 31 of each year. Only the annual register data

5 (updates), available since 1968, are used as the basis for individual statistical registers

6 constructed by Statistics Sweden and for the selection of controls in research. Statistics Sweden

7 also constructs a family register. Previously, the TPR underestimated the number of cohabitants

8 in Sweden (some unmarried individuals living together without common children lacked a formal

9 relation in the register). Through apartment data it is now possible to identify cohabitants living

10 in apartments (approximately half of the population).

\section{UNIQUE IDENTIFIERS}

\section{Personal identity number (PIN)}

14 Linking data in the PRs with other data is possible through the use of the PIN [1]. The PIN

15 consists of birthdate, birth number and a check digit. A detailed description of its construction has been published elsewhere [1]. The vast majority of children born in Sweden receive a PIN at birth. Almost all Swedish delivery units have an "e-birth" system. This system, initiated in 2009, generates a PIN when the delivery nurse enters the sex and time of birth of the newborn. Before 2009, a newborn would receive his or her PIN only 2 weeks after birth; prior to that time, identities were tracked using reserve numbers (in some instances also called "patient number”). Healthcare contacts during the first 2 weeks were sometimes incompletely linked to the correct PIN, especially for same-sex twins. There is no key between reserve numbers and PINs on a national level.

Children born outside Sweden will be assigned a PIN in special circumstances. These circumstances include a child being born to a Swedish diplomat or Swedish State employee or according to special arrangements. For example, some Swedish women may choose to deliver their babies in nearby countries such as Norway or Finland because of the long distance to Swedish hospital care facilities. Children born in Sweden to foreign diplomats are not assigned a PIN and do not enter the PRs. 
1 Immigrants can be assigned a PIN provided they plan to stay in Sweden for $\geq 1$ year AND (i) are

2 employed, (ii) have been admitted to $\geq 1$ year of studies or (iii) provide evidence that they can

3 support themselves. Similar rules apply to individuals from the European Economic Area (EEA)

4 and individuals outside the EEA.

\section{Coordination number}

7 An individual planning to stay in Sweden for less than 1 year can be assigned a unique identifier

8 that is permanently attached to him/her: the coordination number [1]. This unique identifier is

9 similar in structure to the PIN, except that the number 60 is added to the birthday. This means

10 that an individual born on the May 21, 1968 is assigned a coordination number beginning

11 19680581. The number of individuals who have ever had a coordination number is currently

12 estimated at $1,000,000$. This figure includes individuals with the older "total population number"

13 ("TP number"; in use until 1999), which was a temporary PIN preceding the use of the

14 coordination number. Individuals with a coordination number may later receive a PIN.

The purpose of the coordination number is to help government agencies and society to keep track

of individuals without a PIN, as well as to facilitate communication within and between government agencies. For an individual to receive a coordination number, the identity (name, date of birth, place of birth and citizenship) of that individual must be established. Coordination numbers are administered by the Swedish Police, the Swedish Tax Agency and universities (for

21 temporary foreign students).

Coordination numbers are stored in the Reference Register maintained by the Swedish Tax

24 Agency. Besides the coordination number this register stores data on name, citizenship, city and country of birth, and allows for the linkage between a coordination number and a PIN in the same individual. Individuals with coordination numbers are not included in the PRs. 
2 Aspects of coverage

3 Although theoretically the PRs should cover everyone in Sweden, in reality this may not be the

4 case. Individuals who should be in the PRs or have been in the PRs in Sweden make up the target

5 population of the register. The total population in a certain year consists of all individuals who

6 have been in the PRs at some time during that year. For this, the individuals must have lived in

7 Sweden during at least $1 / 7^{\text {th }}$ (i.e. 52 days) of the time during that year.

9 When newborns (e.g., born at home) or immigrants are not reported to the PRs, coverage of the registers is decreased. It is estimated that $<0.1 \%$ of newborns are not reported to the PRs within 30 days. Because of the comprehensive administrative process at immigration, the time from entry to Sweden to registration may be longer than that of newborns. Naturally, the PRs fail to take illegal immigrants into account.

The PRs may also overestimate the number of individuals in Sweden. Some emigrants estimate that they may benefit from remaining in the PRs and therefore fail to report emigration. Individuals who truly stay abroad for $\geq 1$ year (and who should be removed from the PRs) contribute to over-coverage of the PRs. The over-coverage has been estimated to $0.1 \%$ for Nordic citizens but substantially higher for individuals born outside the Nordic countries (potentially 48\%)(personal communication: Karin Wegfors, Statistics Sweden, May 29, 2015). One way of analysing over-coverage is to examine the relative mortality among individuals born outside Sweden vs. those born in Sweden. Death taking place among individuals who have spent a long time abroad may not be reported to the PRs and hence people leaving Sweden without reporting their emigration may seem to live longer than feasible. The Swedish Tax Agency regularly audits all individuals aged >100 years in Sweden; the last audit was in 2012.

In a report published by Statistics Sweden in 2015 [5], the agency writes that low mortality in

28 foreign-born individuals in the PRs suggest that a substantial number of individuals (from the age of 1 year or older) are not residing in Sweden. Figures vary over time. Over-coverage of individuals born in the other Nordic countries has been estimated at 5-20,000 individuals.

31 Because of the vast discrepancies in numbers, Statistics Sweden has recently suggested a 
1 regression model based on a number of indicators (commuting to a neighbouring country,

2 academic studies, inactivity followed by death, whether events in the same family occur, income

3 and migration data). According to this model, the over-coverage in the PRs was between 39,000

4 and 60,000 individuals in 2000-2010. Statistics Sweden currently estimates that over-coverage is

5 equal to $0.25-0.5 \%$ of the Swedish population (personal communication, Karin Wegfors,

6 Statistics Sweden, May 29, 2015). A consequence of over-coverage is that individuals who have

7 truly emigrated contribute risk time when selected for registry-based research, but no data on

8 outcome measures.

\section{Quality of the PRs}

11 The quality of PR data is generally regarded as high. Most data on births, deaths and civil status

12 are reported by professional and administrative personnel such as midwives, physicians, court

13 officials and wedding officials. However, quality may be lower when it comes to change of

14 residence within Sweden or migration in that reporting of data in these areas depends on the

15 individual.

One way to increase the quality of data is through regular audits. Statistics Sweden uses the return of tax declarations (every year) and voting cards (on Election day, every $4^{\text {th }}$ year) because of missing addressees as a means to correct errors. Another aspect of quality is timeliness. Swedish government agencies try to avoid delay of notifications. It has been estimated that $94 \%$ of all births are reported to the Swedish Tax Agency within 2 days and another 6\% (totalling almost 100\%) within 30 days. Missing data are estimated at $0.1 \%$ of all births. Corresponding figures for death, immigration, emigration and change of residence within Sweden are presented in Figure 3. The proportion of immigrants registered within 30 days may vary with circumstances and is likely lower when the Swedish customs is overstrained because of high demands from asylum seekers. On rare occasions, the delay in reporting means that a death or a birth is actually reported during the wrong year (almost always reported in the following year), thereby incorrectly influencing the estimated total population of Sweden in that year. Approximately $0.2 \%$ of all births are reported in the year next to the actual birth year (most of these births likely took place on Dec 31). 
USE OF THE TPR

2 Outside research

3 The PRs are used both internally and externally. Internal use consists of the official population

4 statistics of Sweden, where the population is presented according to sex, age, civil status and

5 place of residence. Vital status, divorce, immigration and emigration are also presented (several

6 times each year). From the TPR, Statistics Sweden randomly selects a small number of

7 individuals who are interviewed in detail in order to survey the workforce, household expenses,

8 and living standard.

10 The TPR serves external users such as decision makers (e.g., those planning for child care, care

11 of the elderly, schools, healthcare and housing construction), government departments and

12 agencies (e.g. the National Board of Health and Welfare (Swedish: Socialstyrelsen) uses TPR

13 data to calculate various subsidies and allowances), but also private companies, organisations and

14 individuals (including media and journalists).

\section{Research use}

17 The TPR is a fundamental part of epidemiological research in Sweden. Knowledge of the number

18 of individuals in a certain year or in a certain part of Sweden allows researchers to calculate both prevalence and incidence of diseases [6 7].

Data on immigration allow for research on health among immigrants, [8] as well as on the aetiology of disease [9]. Lindblad et al found that ADHD medication was more common among international adoptees than in a comparison population [10], but adoption has also been linked to and risk of certain psychiatric diseases in childhood [11].

Bjorkenstam et al recently showed that divorce increases the risk of newly onset psychiatric disease [12]. Wallby et al examined the healthcare contact pattern and immunisation status in 28 children to single vs. cohabiting mothers [13]. The TPR contains extensive information on

29 familial relations and is the basis for the Multi-generation Register [4]. The Multi-generation 
1 aggregates in certain families [14] and that maternal bereavement in the year preceding

2 pregnancy is linked to the risk of stillbirth [15].

3

4 The TPR also contains geographical information, including street address and apartment data (the

5 latter is the basis for information on households). This information allows for studies on

6 socioeconomic gradients and health [16] using Statistics Sweden's "Small Area Marketing

7 Statistics" (SAMS) classification system.

9 Migration within Sweden has implications for the selection of controls in register-based research

10 in that controls are often matched on residence (county, city and/or parish). A girl born in

11 Uppsala County in 1974 would have had her complete inpatient care recorded in the National

12 Patient Register from birth [17]. If this girl then moved to another county in 1977, she could no

13 longer serve as a matched control to other girls in Uppsala county because her comorbidity may

14 not have been completely recorded in the new county (the National Patient Register only became

15 nationwide in 1987).

17 Date of death is useful for researchers examining overall mortality [18]. As opposed to the Cause

18 of Death Register, the TPR does not contain any data on cause of death and only allows the

19 identification of deceased individuals. Furthermore, TPR data on date of death, as well as date of

20 emigration are often used to calculate a correct follow-up time in cohort studies[19-26].

22 Importantly, the TPR is also used to identify controls for cohort and case-control studies [27 28].

23 Some Swedish epidemiological researchers will - after relevant approval by a Regional Ethical

24 Review Board - ask the National Board of Health and Welfare to identify individuals with a

25 certain disease and then ask Statistics Sweden to identify matched controls[27 29-32]. 
2 Statistics Sweden, and indirectly the TPR, is regulated by the personal data act (1998:204), as

3 well as by additional regulations and laws on the treatment of personal data. As opposed to data

4 in the PR-Tax where most data are public, data in the TPR are confidential and protected by the

5 Secrecy Act (chapter 9, §4). This act stipulates that data become confidential on transmission to

6 Statistics Sweden. However, personal data from Statistics Sweden may still be delivered to

7 researchers after appropriate approval by an Ethical Review Board and by an additional review

8 by Statistics Sweden [33]. This means that even if there is an approval from the (Regional)

9 Ethical Review Board, Statistics Sweden may still deny researchers access to TPR data.

10 Statistics Sweden usually delivers de-identified data for research. There is currently no EU

11 regulation for any of the population registers in Sweden, but an agreement on a unified data

12 protection plan has been reached in the so-called Trilogue (the General Data Protection

13 Regulation, GDPR)[34].

15 Confidentiality/secrecy in the TPR is of special relevance if access to data may harm an individual (see also our paper on the PIN [1].) For instance, certain individuals may have a protected address or a change of PINs for security reasons. Certain personal data are regarded as especially sensitive (e.g., those that relate to adoption and citizenship). Special safety precautions should also protect e.g. (i) women who have divorced their husband and when there is a credible threat to the woman or her family, (ii) individuals who are persistently harassed by political opponents (especially immigrants harassed by their former regime), (iii) some judicial personnel (e.g., policemen working with serious crime) and (iv) participants in witness protection programs. In October 2014 , some 13,000 individuals ( $0.1 \%$ of the Swedish population) had a protected

24 identity status. Only for certain purposes will Statistics Sweden deliver data on individuals with a 25 security indicator signalling protected identity. However, individuals with protected identity are included in the housing census. When individuals are persecuted and at high risk, the Tax Agency may allow these persons to keep their recorded place of residence even if they move to another 28 part in the country ("kvarskrivning"). This exception is currently relevant to about 2000 people in 29 Sweden [35]. 
Several ethical aspects are relevant in epidemiological research using the TPR [33], and include

2 the use of large-scale data without prior informed consent of study participants, and the risk of

3 breaching the identity of study participants should the data be accessed by non-researchers or for

4 inappropriate purposes [33]. Meanwhile, the use of already collected data with national coverage

5 allows for the creation of large and unbiased study populations, minimises costs for data

6 collection, and eliminates certain selection bias.

\section{DISCUSSION}

9 The PRs in Sweden have a long history and are an important component of medical research. While the primary aim of national registration is to provide complete population-based data to help the government and other agencies make correct decisions, the data can also be used for

12 medical research. The content of the PR-Tax and the TPR is very similar. Statistics Sweden does however link TPR data to additional individual-based data, and serves medical researchers with data. Similar PRs are also available in other Nordic countries [33]. Given the comparable legal frameworks and handling of ethics applications, it is natural that there is already a number of Nordic research collaborations involving the Swedish TPR [36-39]. As mentioned above, the TPR can be used for a range of research purposes, including follow-up of study participants as it contains data on date of death and emigration. It can also be used for selection of controls and study participants in cohort studies. Of utmost importance in epidemiological research is that controls and cases are selected from the same source population [40]. Data on residence of living is also important given the different coverage of the National

The main strengths of the national PRs of Sweden are their completeness and the link to the PIN [1] allowing data linkage and consistency of definitions (few variables have changed in the past 40 years). The registers have some limitations. One minor limitation is that children with separated parents can have only one registered address, although they may alternate between several addresses [41]. Some students moving for academic studies fail to report their move: a study from the Uppsala County in 2011 found that $15 \%$ of full-time students in Uppsala (a city with a large student population) had a registered address other than Uppsala [5]. Furthermore, the PRs do not record more than one citizenship when an individual is Swedish. 
1 Another minor limitation is incorrect data. A comparison of the PR-Tax and the TPR in 2011

2 found major discrepancies in about 500 individuals (this however amounts to less than 6/100,000

3 registered individuals).

4 The major limitation of the population registers is probably incorrect coverage. Undercoverage is

5 usually of a temporary nature (for example immigrants and deaths not yet recorded), whereas

6 over-coverage may be a more serious issue, even if equivalent only to $0.25-0.5 \%$ of the registered

7 Swedish total population. This figure includes individuals who have died abroad where death has

8 not been reported to Swedish government agencies. Researchers using the family database (the

9 multi-generation part [4]) of the TPR should also be aware of the left-truncation of data. In

10 Sweden, the PIN was initiated in 1947. At that time, all living parents to individuals aged $\leq 15$

11 years were recorded, but parents of individuals born in 1931 or earlier were not recorded.

12 Parental data are also missing to a larger extent when parents have been born abroad [4]. While

13 the TPR registers de jure parenthood, a small proportion of fathers are not the de facto fathers. In

14 most large-scale epidemiological studies, this misclassification is likely to have little influence on

15 research findings as non-paternity (while varying between countries) seem to occur in less than

$165 \%$ of births in most populations [42].

Data on PIN changes are important for medical research in the sense that without knowledge of

PIN changes, the medical history of one individual might mistakenly be merged and assigned to two individuals. Throughout time, PINs have been re-used ( $\mathrm{n}>15,000$ individuals) [1]. This could potentially result in morbidity from two individuals (or births in two women) being incorrectly assigned, as happening in the same individual had not Statistics Sweden kept a record on re-used 23 PINs.

24 When delivering data to researchers, Statistics Sweden will assign one serial number to an

25 individual with two PINs, and all of his or her healthcare history will be linked to that serial number. If two different individuals have been given the same PIN (re-use of the PIN), Statistics

27 Sweden will nevertheless assign two serial numbers to the two individuals so that, e.g., death or

28 "first offspring" will not occur twice in the same individual. 


\section{Acknowledgment}

2 Jonas F. Ludvigsson would like to dedicate this paper to Ingvar Johannesson, former civil servant

3 at Statistics Sweden, neighbour and friend. Johannesson authored the report Total Population

4 Register 2002 BEO1O2. Ludvigsson would also like to acknowledge the help of secretary

5 Angelica Netterhall, Karin Wegfors (Statistics Sweden), Jesper Brodin (Statistics Sweden) and

6 Gunnilla Autio (Swedish Tax Agency). We acknowledge financial support from the Swedish

7 Research Council through the Swedish Initiative for Research on Microdata in the Social And

8 Medical Sciences (SIMSAM) framework grant no. 340-2013-5867. 
Table 1. Selected variables in the Total Population Register (TPR) at Statistics Sweden

\begin{tabular}{|c|c|c|c|}
\hline Variable & $\begin{array}{l}\text { Additional data stored in the TPR } \\
\text { on each individual }\end{array}$ & $\begin{array}{l}\text { EU } \\
\text { variables* }\end{array}$ & Family variables§ \\
\hline $\begin{array}{l}\text { Personal identity number } \\
\text { (PIN) }\end{array}$ & $\begin{array}{l}\text { PIN data on husband/wife, partner, } \\
\text { biological mother, biological father, } \\
\text { parent, child, adopted children (as well } \\
\text { as children "adopted away"), adoptive } \\
\text { mother, adoptive father and "other } \\
\text { persons", including custodians (all the } \\
\text { above individuals are sometimes } \\
\text { called "relation persons") }\end{array}$ & & $\begin{array}{l}\text { Family identity per } \\
\text { household }\end{array}$ \\
\hline \multicolumn{4}{|l|}{$\begin{array}{l}\text { Confidential/protected } \\
\text { identity }\end{array}$} \\
\hline Sex & $\begin{array}{l}\text { Sex of partner and of relation } \\
\text { person(s) are also recorded }\end{array}$ & & \\
\hline \multicolumn{4}{|l|}{$\begin{array}{l}\text { Name: Given name, middle } \\
\text { name, family name }\end{array}$} \\
\hline Civil status & $\begin{array}{l}\text { Duration, dates and changes in civil } \\
\text { status (see text for categories) }\end{array}$ & Civil status & $\begin{array}{l}\text { Type of family. } \\
\text { Number of } \\
\text { individuals in the } \\
\text { family. Number of } \\
\text { children. }\end{array}$ \\
\hline \multicolumn{4}{|l|}{ Duration of marriage } \\
\hline $\begin{array}{l}\text { Date entering the } \\
\text { population registers }\end{array}$ & $\begin{array}{l}\text { Data on register entry also for } \\
\text { adoptive fathers, adoptive mothers and } \\
\text { custodians }\end{array}$ & & \\
\hline Date of deregistration & $\begin{array}{l}\text { Date when an individual is removed } \\
\text { from the population registers (usually } \\
\text { on emigration) }\end{array}$ & & \\
\hline \multicolumn{4}{|l|}{ Birth-related data } \\
\hline Date of birth & $\begin{array}{l}\text { Date of adoption and date of custody } \\
\text { are also registered }\end{array}$ & & \\
\hline Parish at birth \# & From January 2016, district/city at & & \\
\hline
\end{tabular}




\begin{tabular}{|c|c|c|c|}
\hline & $\begin{array}{l}\text { birth will be recorded for all newborns } \\
\text { instead of parish }\end{array}$ & & \\
\hline Country of birth & $\begin{array}{l}\text { Of the individual and of his/her } \\
\text { parents }\end{array}$ & $\begin{array}{l}\text { Country and } \\
\text { region of } \\
\text { residence }\end{array}$ & \\
\hline County of birth & For individuals born in Sweden & & \\
\hline $\begin{array}{l}\text { Age in years and days on } \\
\text { Dec } 31 \text { (current year) }\end{array}$ & & Age & $\begin{array}{l}\text { Number of children } \\
\text { below the ages } 6 \\
\text { years, } 18 \text { years, } 22 \\
\text { years. Number of } \\
\text { children born. Age } \\
\text { of youngest child } \\
\text { in family }\end{array}$ \\
\hline Birth order $\infty$ & $\begin{array}{l}\text { Birth order of the father and mother is } \\
\text { also recorded }\end{array}$ & & \\
\hline \multicolumn{4}{|l|}{ Address data } \\
\hline $\begin{array}{l}\text { Address including postal } \\
\text { area }\end{array}$ & $\begin{array}{l}\text { Up to four addresses in Sweden or } \\
\text { abroad can be registered }\end{array}$ & $\begin{array}{l}\text { Degree of } \\
\text { urbanization }\end{array}$ & \\
\hline Housing/residence & $\begin{array}{l}\text { Includes information on household } \\
\text { since } 2011\end{array}$ & & \\
\hline \multicolumn{4}{|l|}{ Other } \\
\hline \multicolumn{4}{|l|}{ Income } \\
\hline \multicolumn{4}{|l|}{ Origin } \\
\hline \multicolumn{4}{|l|}{$\begin{array}{l}\text { Date of immigration, } \\
\text { country of immigration, } \\
\text { municipality }\end{array}$} \\
\hline County code & Name of county & & \\
\hline \multicolumn{4}{|l|}{ County } \\
\hline \multicolumn{4}{|l|}{ Citizenship } \\
\hline \multicolumn{4}{|l|}{ Date of citizenship } \\
\hline $\begin{array}{l}\text { Emigration: Date and } \\
\text { country }\end{array}$ & $\begin{array}{l}\text { If the individual has emigrated to } \\
\text { another Nordic country, the city in the } \\
\text { new country is recorded }\end{array}$ & & \\
\hline
\end{tabular}


TPR, Total Population Register.

\section{EU, European Union.}

*Statistics Sweden also stores a set of EU variables.

$\S$ Data are usually registered for "family" and separately for "household" (the latter may include more individuals than the family). $\infty$ Birth order refers to all children of the same mother. Until 1973, "birth number" only applied to children born within a marriage. \# Until 1999, it was possible to be born in a non-territorial parish in Sweden. There used to be five non-territorial parishes in the Church of Sweden: the German congregation in Stockholm, the Finnish congregation in Stockholm, the congregation of the Royal Court, the admiralty in Karlskrona and the German congregation in Gothenburg. None of these parishes formally exists since 1999. From 2016, national registration in newborns will consider "city" (Swedish kommun) and no longer parish. 
Figure 1. The Swedish population by year and age group from 1968 to 2014.



Legend: The total population exceeded 8 million in 1979 and 9 million in 2004. Of note, the number of individuals aged $85+$ years has increased from $61,000(0.8 \%$ of the population) in 1968 to 256,000 (2.6\% of the population) in 2014. Meanwhile, the number of children aged 0-14 years has remained relatively constant (1,658,000 (20.9\% of the population) in 1968 and $1,682,000$ (17.3\% of the population) in 2014).

Data originate from Statistics Sweden (access date: June 2, 2015:

http://www.statistikdatabasen.scb.se).

Figure 2. Flowchart: The Swedish Tax Agency delivers data to Statistics Sweden and its Total Population Register (TPR). 
Births, immigration, emigration, deaths, movements within Sweden, marriages, divorces, changes of citizenship etc.
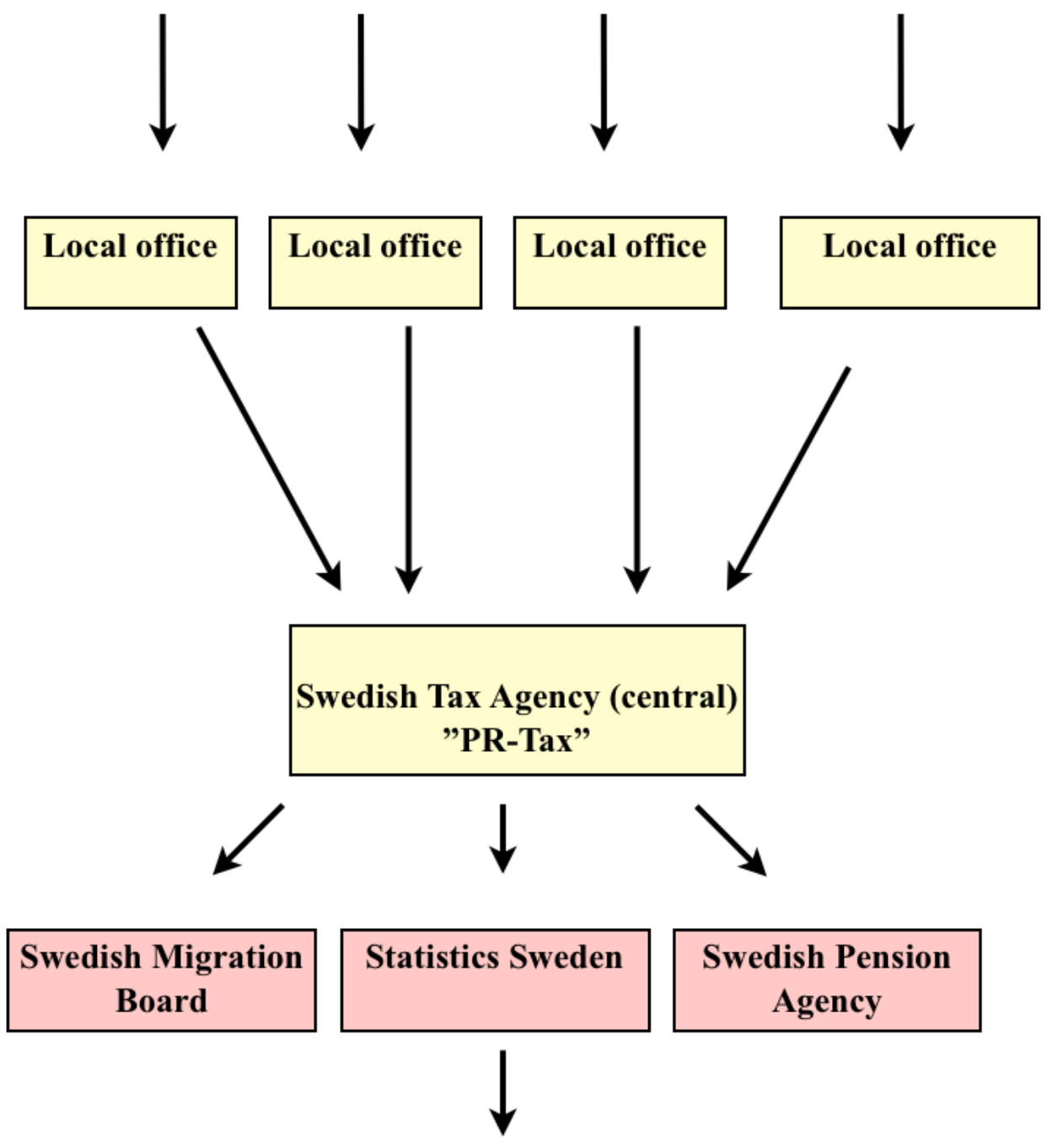

\section{Total Population Register} (TPR)

1

2

3 Legend: In 2015, the Swedish Tax Agency had 103 local offices.

4

$5 \quad$ Figure 3. Coverage (\%) of vital status and migration data in Swedish population registers. 


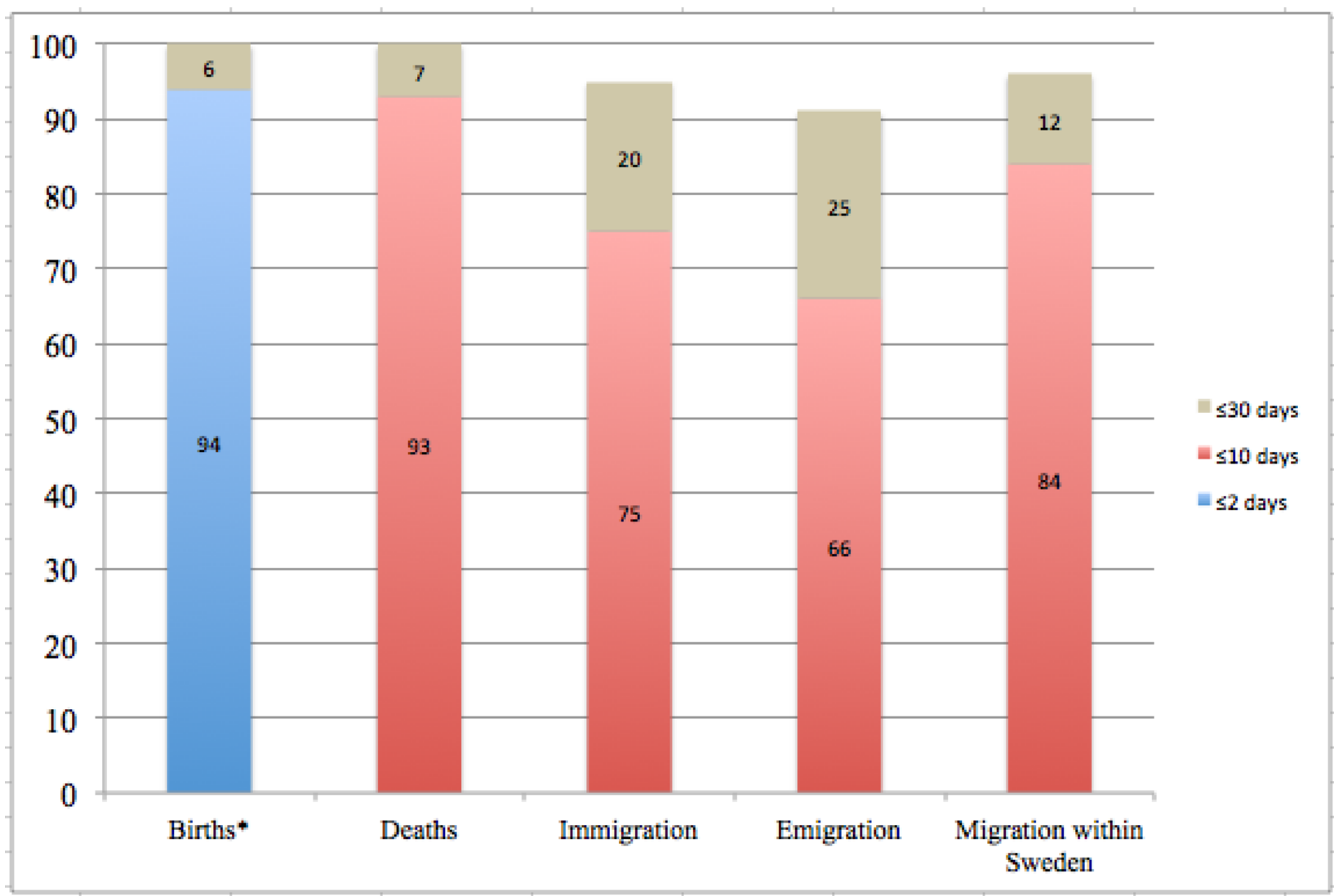

Legend: Data refer to \% within 10 days (red) and within 30 days (brown), except for birth data* where the " $94 \%$ " refers to $\leq 2$ days (blue). About $75 \%$ of all immigrations are reported to the

5 Swedish Tax Agency within 10 days and another $20 \%$ are reported within 30 days (totalling $695 \%)$. 


\section{REFERENCES}

1. Ludvigsson JF, Otterblad-Olausson P, Pettersson BU, Ekbom A. The Swedish personal identity number: possibilities and pitfalls in healthcare and medical research. Eur J Epidemiol 2009;24(11):659-67.

2. Swedish_National_Tax_Agency. Den svenska folkbokföringens historia under tre sekler [English: The Swedish national population registration - history of the last 300 years], 2015.

3. Statistics_Sweden (Swedish: Statistiska Centralbyrån S. Olika familjer lever på olika sätt - om barns boende och försörjning efter en separation. Demogragfiska rapporter 2014:01 [English: Different families have different ways of living - about children's living and support after a separation], 2014.

4. Ekbom A. The Swedish Multi-generation Register. Methods Mol Biol 2011;675:215-20.

5. Statistics_Sweden (Swedish: Statistiska Centralbyrån S. Overcoverage in the Total Population Register - a register study. Background facts. Population and Welfare 2015:1., 2015.

6. Eriksson JK, Neovius M, Ernestam S, Lindblad S, Simard JF, Askling J. Incidence of rheumatoid arthritis in Sweden: a nationwide population-based assessment of incidence, its determinants, and treatment penetration. Arthritis Care Res (Hoboken) 2013;65(6):870-8.

7. Busch K, Ludvigsson JF, Ekstrom-Smedby K, Ekbom A, Askling J, Neovius M. Nationwide prevalence of inflammatory bowel disease in Sweden: a population-based register study. Aliment Pharmacol Ther 2014;39(1):57-68.

8. Johansson B, Helgesson M, Lundberg I, Nordquist T, Leijon O, Lindberg P, Vingard E. Work and health among immigrants and native Swedes 1990-2008: a register-based study on hospitalization for common potentially work-related disorders, disability pension and mortality. BMC Public Health 2012;12:845.

9. Ji J, Ludvigsson JF, Sundquist K, Sundquist J, Hemminki K. Incidence of celiac disease among second-generation immigrants and adoptees from abroad in Sweden: evidence for ethnic differences in susceptibility. Scand J Gastroenterol 2011;46(7-8):844-8.

10. Lindblad F, Weitoft GR, Hjern A. ADHD in international adoptees: a national cohort study. Eur Child Adolesc Psychiatry 2010;19(1):37-44.

11. Wicks S, Hjern A, Dalman C. Social risk or genetic liability for psychosis? A study of children born in Sweden and reared by adoptive parents. Am J Psychiatry 2010;167(10):1240-6.

12. Bjorkenstam E, Hallqvist J, Dalman C, Ljung R. Risk of new psychiatric episodes in the year following divorce in midlife: cause or selection? A nationwide register-based study of 703,960 individuals. Int J Soc Psychiatry 2013;59(8):801-4.

13. Wallby T, Modin B, Hjern A. Child health care utilisation in families with young or single mothers in a Swedish county. J Child Health Care 2012.

14. Frisell T, Lichtenstein P, Langstrom N. Violent crime runs in families: a total population study of 12.5 million individuals. Psychol Med 2011;41(1):97-105.

15. Laszlo KD, Svensson T, Li J, Obel C, Vestergaard M, Olsen J, Cnattingius S. Maternal bereavement during pregnancy and the risk of stillbirth: a nationwide cohort study in Sweden. Am J Epidemiol 2013;177(3):219-27.

16. Sariaslan A, Larsson H, D'Onofrio B, Langstrom N, Fazel S, Lichtenstein P. Does population density and neighborhood deprivation predict schizophrenia? A nationwide Swedish family-based study of 2.4 million individuals. Schizophr Bull 2015;41(2):494-502. 
17. Ludvigsson JF, Andersson E, Ekbom A, Feychting M, Kim JL, Reuterwall C, Heurgren M, Otterblad Olausson P. External review and validation of the Swedish national inpatient register. BMC Public Health 2011;11(1):450.

18. Ludvigsson JF, Montgomery SM, Ekbom A, Brandt L, Granath F. Small-intestinal histopathology and mortality risk in celiac disease. JAMA 2009;302(11):1171-8.

19. Herweijer E, Leval A, Ploner A, Eloranta S, Simard JF, Dillner J, Netterlid E, Sparen P, Arnheim-Dahlstrom L. Association of varying number of doses of quadrivalent human papillomavirus vaccine with incidence of condyloma. JAMA 2014;311(6):597-603.

20. Melander O, Maisel AS, Almgren P, Manjer J, Belting M, Hedblad B, Engstrom G, Kilger U, Nilsson P, Bergmann A, Orho-Melander M. Plasma proneurotensin and incidence of diabetes, cardiovascular disease, breast cancer, and mortality. JAMA 2012;308(14):146975.

21. Melander O, Newton-Cheh C, Almgren P, Hedblad B, Berglund G, Engstrom G, Persson M, Smith JG, Magnusson M, Christensson A, Struck J, Morgenthaler NG, Bergmann A, Pencina MJ, Wang TJ. Novel and conventional biomarkers for prediction of incident cardiovascular events in the community. JAMA 2009;302(1):49-57.

22. Ludvigsson JF, Welander A, Lassila R, Ekbom A, Montgomery SM. Risk of thromboembolism in 14,000 individuals with coeliac disease. Br J Haematol 2007;139(1):121-7.

23. Ludvigsson JF, Olsson T, Ekbom A, Montgomery SM. A population-based study of coeliac disease, neurodegenerative and neuroinflammatory diseases. Aliment Pharmacol Ther 2007;25(11):1317-27.

24. Song H, Ekheden IG, Zheng Z, Ericsson J, Nyren O, Ye W. Incidence of gastric cancer among patients with gastric precancerous lesions: observational cohort study in a low risk Western population. BMJ 2015;351:h3867.

25. Holmqvist ME, Neovius M, Eriksson J, Mantel A, Wallberg-Jonsson S, Jacobsson LT, Askling J. Risk of venous thromboembolism in patients with rheumatoid arthritis and association with disease duration and hospitalization. JAMA 2012;308(13):1350-6.

26. Bjorkenstam C, Weitoft GR, Hjern A, Nordstrom P, Hallqvist J, Ljung R. School grades, parental education and suicide--a national register-based cohort study. J Epidemiol Community Health 2011;65(11):993-8.

27. Ljung R, Lagergren J, Bexelius TS, Mattsson F, Lindblad M. Increased risk of acute pancreatitis among tetracycline users in a Swedish population-based case-control study. Gut 2012;61(6):873-6.

28. Andersson RE, Olaison G, Tysk C, Ekbom A. Appendectomy and protection against ulcerative colitis. N Engl J Med 2001;344(11):808-14.

29. Lind M, Svensson AM, Kosiborod M, Gudbjornsdottir S, Pivodic A, Wedel H, Dahlqvist S, Clements M, Rosengren A. Glycemic control and excess mortality in type 1 diabetes. N Engl J Med 2014;371(21):1972-82.

30. Lagergren J, Bergstrom R, Lindgren A, Nyren O. Symptomatic gastroesophageal reflux as a risk factor for esophageal adenocarcinoma. N Engl J Med 1999;340(11):825-31.

31. Huang J, Magnusson M, Torner A, Ye W, Duberg AS. Risk of pancreatic cancer among individuals with hepatitis C or hepatitis B virus infection: a nationwide study in Sweden. Br J Cancer 2013;109(11):2917-23.

32. Eriksson JK, Neovius M, Bratt J, Petersson IF, van Vollenhoven RF, Geborek P, Ernestam S. Biological vs. conventional combination treatment and work loss in early rheumatoid arthritis: a randomized trial. JAMA Intern Med 2013;173(15):1407-14. 
33. Ludvigsson JF, Haberg SE, Knudsen GP, Lafolie P, Zoega H, Sarkkola C, von Kraemer S, Weiderpass E, Norgaard M. Ethical aspects of registry-based research in the Nordic countries. Clin Epidemiol 2015;7:491-508.

34. Council_of_the_European_Union. Proposal for a Regulation of the European Parliament and of the Council on the protection of individuals with regard to the processing of personal data and on the free movement of such data (General Data Protection Regulation), 2015. 35. Swedish_National_Tax_Agency. Kvarskrivning.

36. Lichtenstein P, Holm NV, Verkasalo PK, Iliadou A, Kaprio J, Koskenvuo M, Pukkala E, Skytthe A, Hemminki K. Environmental and heritable factors in the causation of cancer-analyses of cohorts of twins from Sweden, Denmark, and Finland. N Engl J Med 2000;343(2):78-85.

37. Furu K, Kieler H, Haglund B, Engeland A, Selmer R, Stephansson O, Valdimarsdottir UA, Zoega H, Artama M, Gissler M, Malm H, Norgaard M. Selective serotonin reuptake inhibitors and venlafaxine in early pregnancy and risk of birth defects: population based cohort study and sibling design. BMJ 2015;350:h1798.

38. Stephansson O, Kieler H, Haglund B, Artama M, Engeland A, Furu K, Gissler M, Norgaard M, Nielsen RB, Zoega H, Valdimarsdottir U. Selective serotonin reuptake inhibitors during pregnancy and risk of stillbirth and infant mortality. JAMA 2013;309(1):48-54.

39. Sandin S, Schendel D, Magnusson P, Hultman C, Suren P, Susser E, Gronborg T, Gissler M, Gunnes N, Gross R, Henning M, Bresnahan M, Sourander A, Hornig M, Carter K, Francis R, Parner E, Leonard H, Rosanoff M, Stoltenberg C, Reichenberg A. Autism risk associated with parental age and with increasing difference in age between the parents. Mol Psychiatry 2015.

40. Fletcher RH, Fletcher SW, Fletcher GS. Clinical epidemiology. The Essentials. 5 ed: Lippincott, Williams \& Wilkins, 2012.

41. Statistics_Sweden (Swedish: Statistiska Centralbyrån S. Different families live in different ways - a survey on residence and support of children after a separation. BE51BR1401., 2014.

42. Bellis MA, Hughes K, Hughes S, Ashton JR. Measuring paternal discrepancy and its public health consequences. J Epidemiol Community Health 2005;59(9):749-54. 